\title{
Sex-Linked Differences in the Course of Thioacetamide-Induced Acute Liver Failure in Lewis Rats
}

\author{
Eva KOBLIHOVÁ ${ }^{1}$, Iveta MRÁZOVÁ ${ }^{2}$, Zdenka VAŇOURKOVÁ ${ }^{2}$, Hana MAXOVÁ ${ }^{2,3}$, \\ Miroslav RYSKA ${ }^{1}$, Jiř́ FRONĚK ${ }^{4}$
}

${ }^{1}$ Department of Surgery, Second Faculty of Medicine, Charles University and Central Military Hospital, Prague, Czech Republic, ${ }^{2}$ Center for Experimental Medicine, Institute for Clinical and Experimental Medicine, Prague, Czech Republic, ${ }^{3}$ Department of Pathophysiology, Second Faculty of Medicine, Charles University, Prague, Czech Republic, ${ }^{4}$ Department of Transplantation Surgery, Institute for Clinical and Experimental Medicine, Prague, Czech Republic

Received May 7, 2020

Accepted June 30, 2020

Epub Ahead of Print September 9, 2020

\section{Summary}

Acute liver failure (ALF) is a clinical syndrome with high mortality rate, resulting from widespread hepatocyte damage. Its pathophysiological background is still poorly understood and preclinical studies evaluating pathophysiology and new potential therapeutic measures are needed. The model of ALF induced by administration of thioacetamide (TAA) in Lewis rats is recommended as optimal; however, the limitation of previous studies was that they were performed predominantly in male rats. In view of the growing recognition that sex as a biological variable should be taken into consideration in preclinical research, we examined its role in the development of TAA-induced ALF in Lewis rats. We found that, first, intact male Lewis rats showed lower survival rate than their female counterparts, due to augmented liver injury documented by higher plasma ammonia, and bilirubin levels and alanine aminotransferase activity. Second, in female rats castration did not alter the course of TAA-induced ALF whereas in the male gonadectomy improved the survival rate and attenuated liver injury, reducing it to levels observed in their female counterparts. In conclusion, we found that Lewis rats show a remarkable sexual dimorphism with respect to TAA-induced ALF, and male rats display dramatically poorer prognosis as compared with the females. We showed that testosterone is responsible for the deterioration of the course of TAA-induced ALF in male rats. In most general terms, our findings indicate that in the preclinical studies of the pathophysiology and treatment of ALF (at least of the TAA-induced form) the sex-linked differences should be seriously considered.

\section{Key words}

Acute liver failure $\bullet$ Thioacetamide $\bullet$ Sex differences $\bullet$ Lewis rats

\section{Corresponding author}

E. Koblihová, Department of Surgery, Second Faculty of Medicine, Charles University and Central Military Hospital, Prague, Czech Republic. E-mail: eva.koblihova@uvn.cz

\section{Introduction}

Acute liver failure (ALF) is a term that applies to the clinical syndrome resulting from widespread hepatocyte damage with consequent loss of liver function. ALF is a syndrome characterized by rapid development in originally healthy individuals (Stravitz and Lee 2019, Weiler et al. 2020). Even though it is a rare organ disorder, in accordance with the register of the Acute Liver Failure Study Group its incidence is estimated at 1 case per million inhabitants (Stravitz and Lee 2019, Weiler et al. 2020), and the overall mortality, before introduction of orthotopic liver transplantation (OLT), was above $80 \%$ (Fyfe et al. 2018, Patel et al. 2018, Stravitz and Lee 2019). Therefore, ALF must be regarded as a serious life-threating condition. There is no doubt that OLT is the only effective therapeutic measure

PHYSIOLOGICAL RESEARCH • ISSN 1802-9973 (online) 
for the treatment of ALF and its introduction to clinical practice reduced the overall mortality to about $33 \%$ (Bernal et al. 2013, Reuben et al. 2016, Stravitz and Lee 2019). However, this treatment has limited application, primarily due to the scarcity of donor organs, particularly those available on emergency notice. In addition, the early post-transplantation mortality in patients with ALF exceeds that of the patients who undergo OLT for liver cirrhosis, which again underscores the severity of clinical condition of ALF patients (Stravitz and Lee 2019, Weiler et al. 2020). Therefore, it is recognized that new strategies for the treatment of this highly lethal condition are urgently needed (Stravitz and Lee 2019, Weiler et al. 2020). However, the prerequisite for the success is the detailed understanding of the pathophysiology of ALF. The problem is that the relevant clinical studies are technically extremely demanding for many reasons, mainly because of the requirement of sufficiently high number of patients for the study. Therefore, functional studies using animal models are urgently needed. After considering various aspects of the research, the models that use hepatotoxic drugs for induction of ALF in the rat were chosen as the most suitable for studies of ALF (Butterworth et al. 2009, Lima et al. 2019, Tuňon et al. 2009). Among a large number of the chemical agents examined, thioacetamide (TAA) is recommended most often (Butterworth et al. 2009, Lima et al. 2019, Tuňon et al. 2009). Over the past 6 years, our laboratory team clearly characterized the course of TAA-induced ALF in Lewis rats, and using this model, we tested two new approaches for the treatment of ALF (Koblihová et al. 2014, Koblihová et al. 2015, Koblihová et al. 2020). In our experience, this experimental model proved most suitable for evaluation of the pathophysiology of ALF and, in particular, for preclinical testing of new therapeutic approaches.

However, it is admitted that our studies have one critically important limitation, i.e. they were performed exclusively in male animals. This is a very common limitation in preclinical research, despite the increasing recognition that studies confined to one sex (usually male) could be one factor contributing to the failure of translation of the experimental results to clinical medicine (Docherty et al. 2019, Lee 2018, Mannon et al. 2020, Zucker and Berry 2019). It will be noticed that the liver is one of the most sexually dimorphic organs, regarding its structure and physiological function (Gustafsson et al. 1983, Marcos et al. 2015, Suchy 2009, Waxman and Holloway 2009, Waxman and O'Connor 2006), the sensitivity to various hepatotoxic insults (Amacher 2014, Buzzett et al. 2017, Mennecozzi et al. 2015, Sutti and Tackle 2018) and, finally, the course of ALF and liver regeneration (Bizzaro et al. 2017, Lee et al. 2019, Rubin et al. 2018, Schotten et al. 2015, Tsukamoto and Kojo 1990, Weiler et al. 2020). Therefore, it is obvious that studies that evaluate the role of sex in the development of TAA-induced ALF in Lewis rats are needed. Accordingly, the first aim of the present study was to compare the development of TAA-induced ALF in healthy male and female Lewis rats. Thenceforward, we evaluated if sexual hormones mediate the presumed sex-linked differences. For this purpose, the classical experimental approach to study sex-linked differences was employed based on the comparison of the course of TAA-induced ALF between intact and gonadectomized male and female Lewis rats (Ostadal et al. 2009, RegizZagrosek and Kararigas 2017).

\section{Methods}

\section{Ethical approval, animals, ALF model}

The studies were performed in accordance with the guidelines and practices established by the Animal Care and Use Committee of the Institute for Clinical and Experimental Medicine, Prague, which accord with the European Convention on Animal Protection and Guidelines on Research Animal Use, and consequently were approved by the Ministry of Health of the Czech Republic (project decision 12353/2018-3/OVZ). The experiments were performed in male and female Lewis rats that were purchased from Charles River Laboratories (Velaz, Prague, Czech Republic) at the age of 8 weeks. Before starting the experiments, the rats were acclimatized in our vivarium during two weeks. The Lewis rats were chosen, because it is an inbred strain and we showed it previously to be suitable for hepatocyte transplantation studies (Koblihová et al. 2015). In order to maintain consistency and reproducibility of the results of all our research using TAA-induced ALF model, we have decided to employ Lewis rats also in the present study.

TAA (Sigma, Prague, Czech Republic) was dissolved in physiological saline and administrated i.p. in two injections, on day 0 at 8:00 $\mathrm{AM}$ and 20:00 $\mathrm{PM}$, in the total amount of $525 \mathrm{mg} / \mathrm{kg}$ of body weight (BW). This dose was chosen based on our original study evaluating the optimal dose of TAA for induction of ALF in Lewis rats and it was used in all our studies in this model 
(Koblihová et al. 2014, Koblihová et al. 2015, Koblihová et al. 2020). By employing this dose all Lewis rats developed ALF and, when untreated, succumbed within the first $48 \mathrm{~h}$. Control rats received i.p. injections of physiological saline.

Gonadectomy or sham-operation was performed under thiopental sodium anesthesia, $50 \mathrm{mg} / \mathrm{kg} \quad \mathrm{BW}$ (Thiopental VUAB, Prague, Czech Republic); this was done two weeks before TAA administration. The details of the operation were as described in our previous study (Vaněčková et al. 2011). Briefly, in female rats, the peritoneal cavity was opened and the ovaries and uterus were removed, thereafter the peritoneal cavity was cleaned and the muscle wall and the skin were sutured. In male rats orchiectomy was performed: the ductus deferens was isolated and ligated and then each testicle was removed via midline incision on the scrotum. Butorphanol (Torbugesic, Fort Dodge Animal Health, Fort Dodge, KS, USA), $2 \mathrm{mg} / \mathrm{kg}$ BW, was administered subcutaneously for post-operative analgesia. Fourteen days after sham-operation or gonadectomy, their effectiveness was validated in separate groups of animals by determining plasma levels of testosterone and estradiol, assessed by radioimmunoassay employing commercially available kits (Diagnostic Systems Laboratories, Webster, Texas, USA), see series 1.

\section{Experimental design}

Series 1: Effects of gonadectomy on plasma testosterone and estradiol levels in Lewis rats

Sham-operation or gonadectomy was performed in male and female Lewis rats aged 11 weeks $(n=8$ in each group), and two weeks later the animals were killed by decapitation (to prevent effects of anesthesia on blood hormone levels) and plasma testosterone and estradiol were determined as described above.

Series 2: Effects of gonadectomy on the course of TAA-induced ALF in Lewis rats

The experimental design used in this series is outlined in Figure 1. Like in series 1, male and female Lewis rats aged 11 weeks underwent either shamoperation or gonadectomy, and two weeks later TAA was administered i.p. whereas control animals received physiological saline. Twenty-four hours earlier a blood sample was taken from the tail vein for biochemical analyses (Fuji Drive-Chem 4000 Analyzer). Plasma levels of albumin, bilirubin, alanine aminotransferase (ALT) and aspartate aminotransferase (AST) activity, and ammonia level $\left(\mathrm{NH}_{3}\right)$ were determined. Blood samples for the same analyses were also taken 24, 48, 72, 96 and $168 \mathrm{~h}$ after the first administration of TAA. The followup period in this series was $168 \mathrm{~h}$ and at the end of the experiments, the surviving animals were killed by an overdose of sodium thiopental. Since during ALF development the animals' food and water intake decreased dramatically, 5\% glucose solution, $2 \mathrm{ml} / 100 \mathrm{~g} \mathrm{BW}$, was administered subcutaneously every morning to prevent dehydration; this was done also in control animals. Our recent studies demonstrated the desired effectiveness of this procedure (Koblihová et al. 2014, Koblihová et al. 2015, Koblihová et al. 2020). The survival rate was monitored every $8 \mathrm{~h}$, BW was monitored every $24 \mathrm{~h}$ and blood samples were taken at the time-points described above.

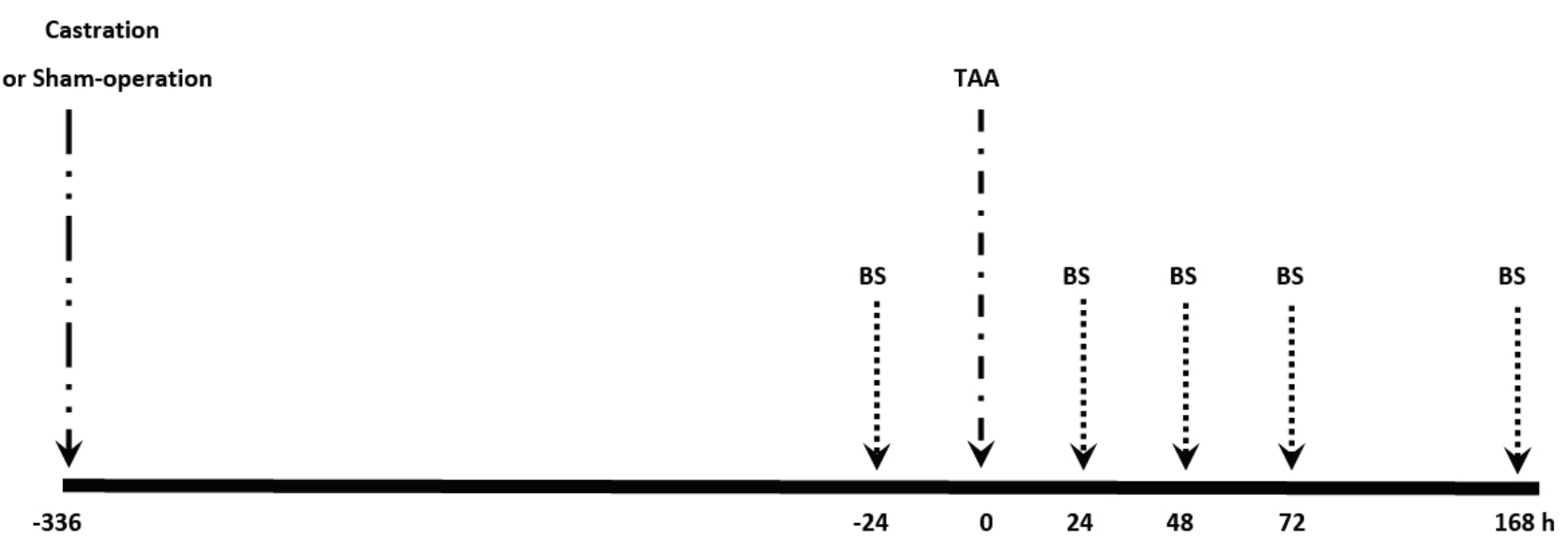

Fig. 1. An outline of the experimental protocol. BS - blood sampling, TAA - administration of thioacetamide in two intraperitoneal injections in the total amount $525 \mathrm{mg} / \mathrm{kg}$ of body weight. 

examined:

The following experimental groups were

1) Male Lewis rats intact + physiological saline (Healthy male rats) (initial $\mathrm{n}=8$ )

2) Male Lewis rats castrated + physiological saline (Healthy male rats + castration) (initial $\mathrm{n}=9$ )

3) Male Lewis rats intact + TAA (Male rats with ALF) (initial $n=30$ )

4) Male Lewis rats castrated + TAA (Male rats with $\mathrm{ALF}+$ castration) (initial $\mathrm{n}=30$ )

5) Female Lewis rats intact + physiological saline (Healthy female rats) (initial $n=9$ )

6) Female Lewis rats castrated + physiological saline (Healthy female rats + castration) (initial $n=10$ )

7) Female Lewis rats intact + TAA (Female rats with ALF) (initial $n=30$ )

8) Female Lewis rats castrated + TAA (Female rats with ALF + castration) (initial $n=30$ )

\section{Statistical analysis}

Statistical analysis of the data was performed using Graph-Pad Prism software (Graph Pad Software, San Diego, CA, USA). Comparison of survival curves was performed by log-rank (Mantel-Cox) test followed by Gehan-Breslow-Wilcoxon test. ANOVA for repeated measurements, followed by Student-Newman-Keuls test, was performed for analysis of changes within the groups. Statistical comparison of other results was made by oneway ANOVA. Unless indicated otherwise, the values are expressed as mean \pm S.E.M. A $\mathrm{P}<0.05$ was considered statistically significant.

\section{Results}

As shown in Figure 2A, in male rats castration caused substantial reduction of testosterone concentration to the level seen in female rats. There was no difference in plasma testosterone levels between intact and castrated female rats and no difference in plasma estradiol levels between intact and castrated male rats (Fig. 2B). On the other hand, plasma estradiol concentration was significantly higher in intact female rats as compared with intact male rats, and gonadectomy decreased plasma estradiol in the females to values observed in the males (Fig. 2B).

As shown in Figure 3A, male as well as female Lewis rats began to die $48 \mathrm{~h}$ after TAA administration but the males exhibited much poorer survival course, and their final survival rate was $37 \%$ (11 of 30 animals) compared to $83 \%$ (25 of 30 animals) in the females. Figure 3B shows that gonadectomy considerably improved the survival rate in male Lewis rats, with the final survival of $93 \%$ (28 of 30 animals), but did not alter the course of survival rate and the final survival rate in the females (Fig. 3C).

A
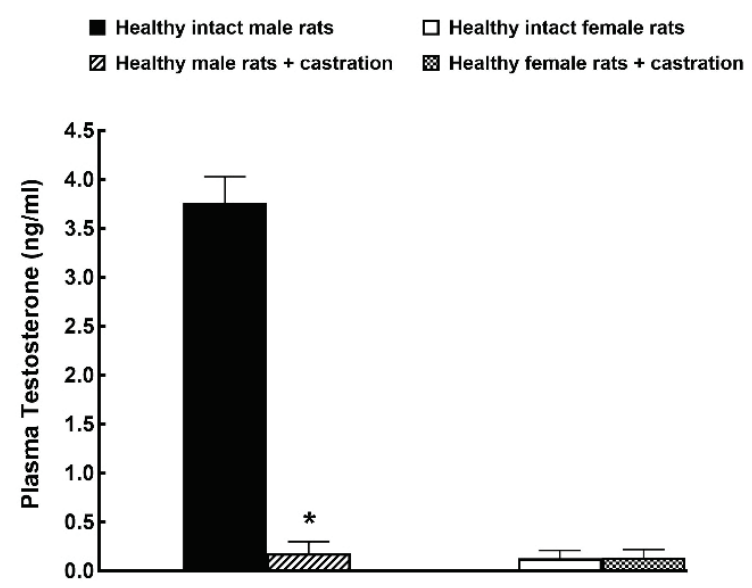

B

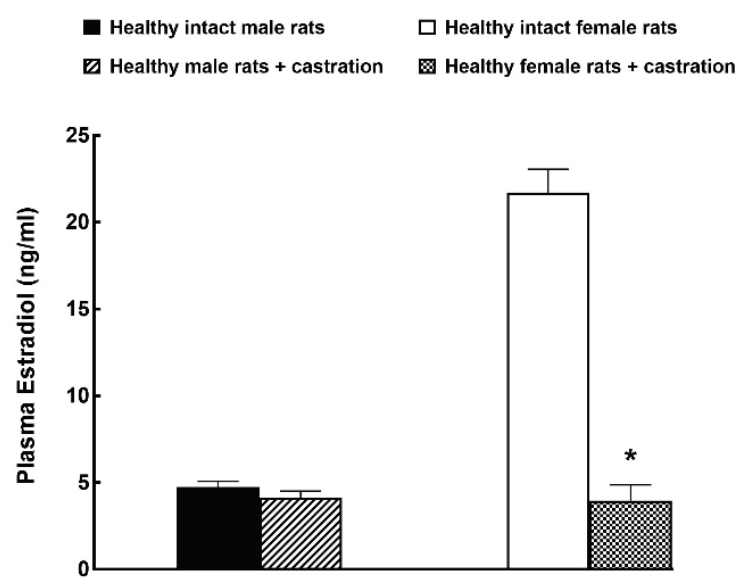

Fig. 2. Plasma testosterone (A) and estradiol (B) levels measured 14 days after sham-operation or castration. $* \mathrm{P}<0.05$ vs. the corresponding intact (not castrated) group.

Prior to TAA administration there were no significant differences in BW between intact and castrated male and female Lewis rats (Fig. 4A and 4B). As expected, BW of the males was significantly higher than in the females, similarly in intact and castrated animals. Intact as well as castrated healthy male rats (i.e. those receiving physiological saline) showed similar slight BW gain throughout the experiment (Fig. 4A). In contrast, TAA treated intact male rats showed a profound decrease in BW seen already $24 \mathrm{~h}$ after administration of the drug, with the maximum BW loss seen $96 \mathrm{~h}$ after TAA administration. In the end, the survived animals still 
showed BW about $80 \mathrm{~g}$ lower than the intact healthy male rats $(280 \pm 8$ vs. $364 \pm 9 \mathrm{~g}, \mathrm{P}<0.05)$ (Fig. $4 \mathrm{~A})$. As shown in Figure $4 \mathrm{~A}$, castration of male rats attenuated the postTAA loss of BW. Figure 4B shows that the females and males displayed similar profiles of BW, except that gonadectomy did not alter the course of BW after TAA administration.

A

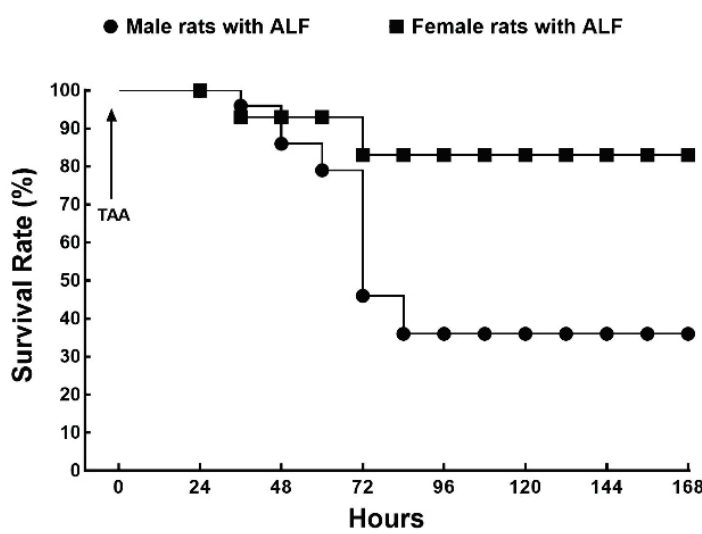

B

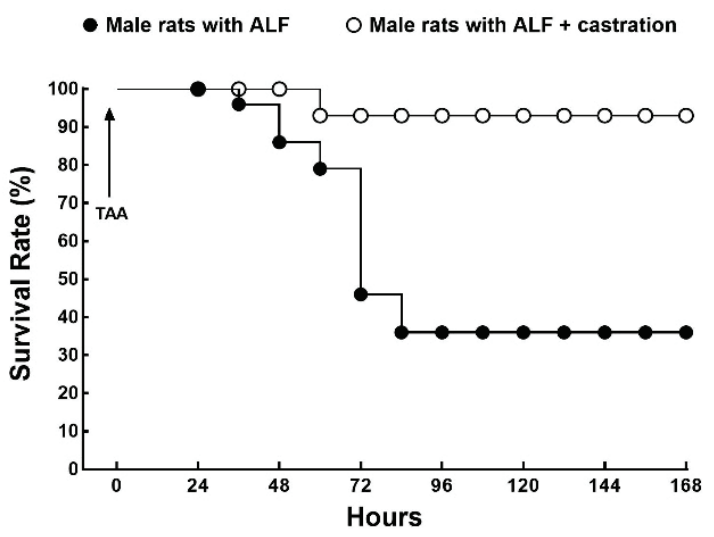

C

- Female rats with ALF $\square$ Female rats with ALF + castration

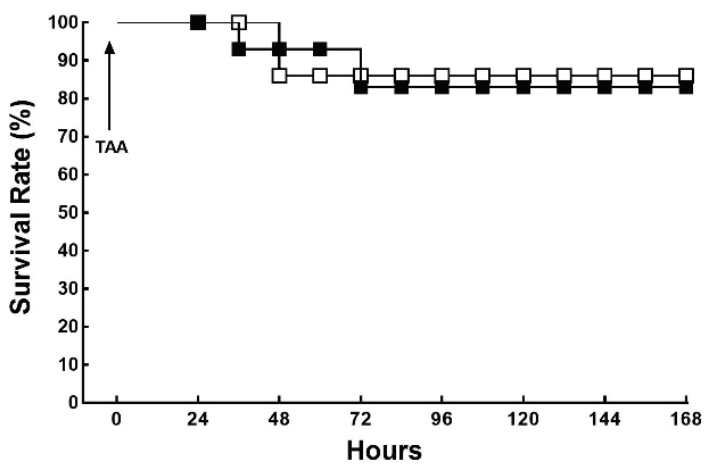

Fig. 3. (A) Comparison of the survival rate in intact male and female Lewis rats with acute liver failure (ALF) induced by thioacetamide (TAA) administration. The survival rate of intact male Lewis rats with ALF was significantly lower than in their female counterparts. (B) In male Lewis rats with ALF, castration significantly improved survival rate as compared with intact males. (C) In female Lewis rats with ALF, castration did not alter the survival rate. The comparison of the survival rate curves was performed by log-rank Mantel-Cox test followed by GehanBreslow-Wilcoxon test.
A

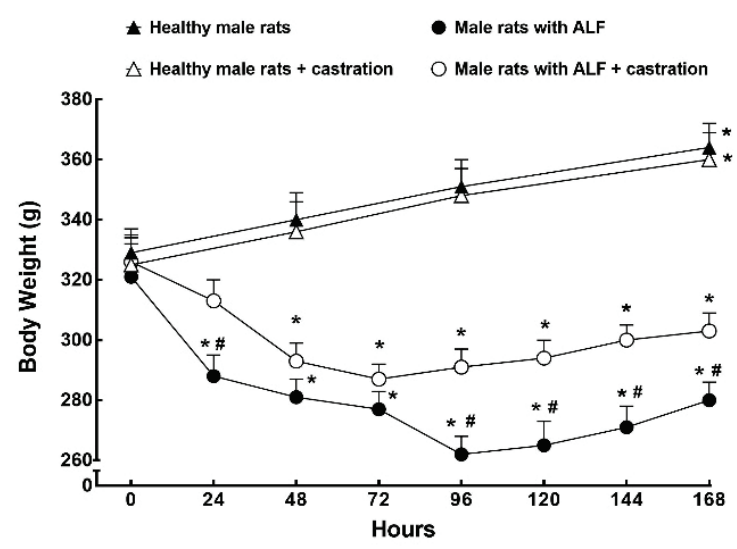

B

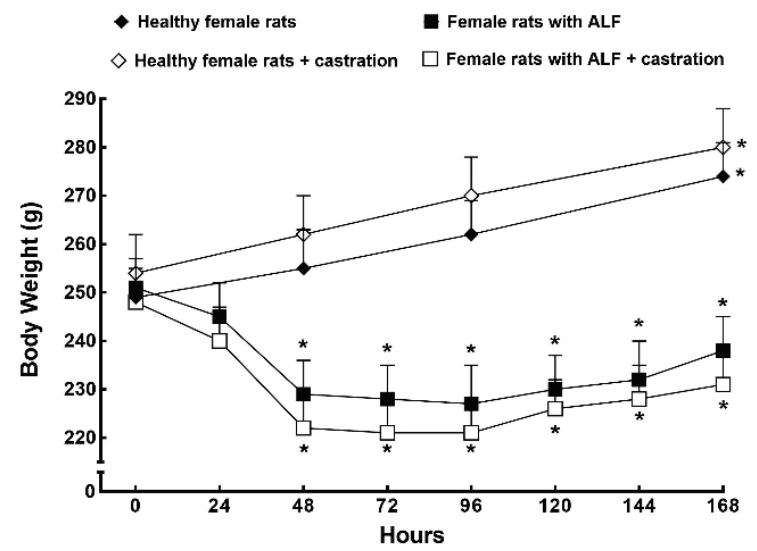

Fig. 4. Changes in body weight in male (A) and female (B) Lewis rats with acute liver failure (ALF) induced by thioacetamide (TAA), intact or castrated, and in intact or castrated male and female Lewis rats. $* P<0.05$ vs. basal values (i.e. at time 0 ) in the same group. ${ }^{\#} P<0.05$ vs. corresponding values at the same time point in castrated male Lewis rats with TAA-induced ALF.

A marked increase in plasma $\mathrm{NH}_{3}$ levels was observed in the first $48 \mathrm{~h}$ after TAA administration and it was more pronounced in intact males than in the females (Fig. 5A). In the animals that survived until the end of experiment (i.e. $168 \mathrm{~h}$ after first TAA injection) $\mathrm{NH}_{3}$ levels were similar as observed in healthy males and females, i.e. the animals injected with physiological saline. In male rats castration attenuated the increase in plasma $\mathrm{NH}_{3}$ reducing it to the levels observed in intact females. In contrast in female rats gonadectomy did not alter the course of changes in plasma $\mathrm{NH}_{3}$ (Fig. 5A).

Likewise (Fig. 5B), TAA administration caused a significant increase in plasma ALT activity, which was more pronounced in intact male rats than in intact females, and in the intact males it remained elevated until the end of experiment (i.e. $168 \mathrm{~h}$ after first TAA injection). In male rats, castration attenuated the increase in plasma ALT seen after TAA injections. In contrast, castration did not alter the course of plasma ALT activity 
in the females. Plasma AST activity showed a similar pattern of changes (data not shown).

As shown in Figure 5C, TAA administration elicited significant elevation of plasma bilirubin levels, which was again more prominent in intact male rats as compared with the females. This figure shows that gonadectomy attenuated this increase in the males but not in the females; this was observed in the case of $\mathrm{NH}_{3}$ levels and ALT and AST activities.

A

Male rats with ALF

$\square$ Female rats with ALF

Male rats with ALF + castration

Female rats with $A L F+$ castration

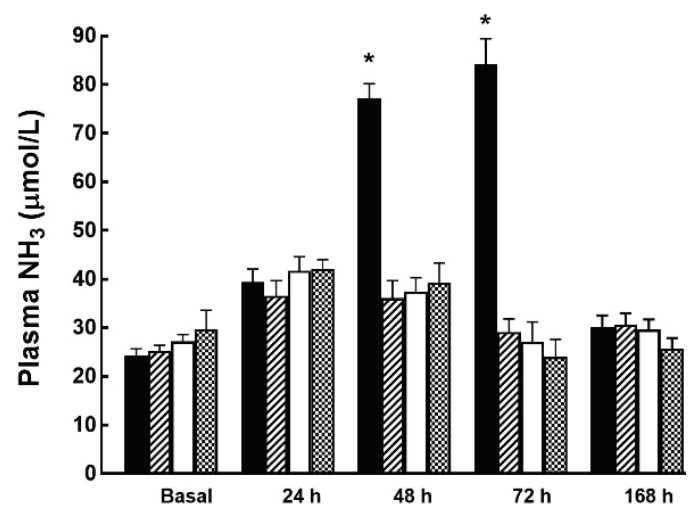

B

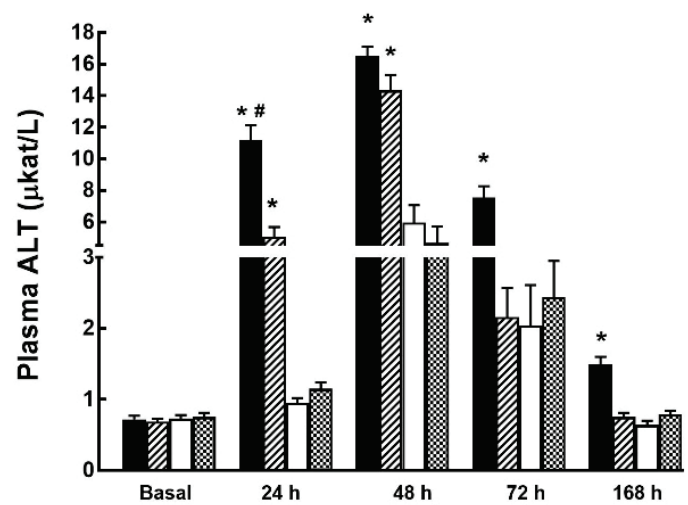

Figure 5D shows that in intact male Lewis rats TAA administration resulted in a progressive decrease in plasma albumin with maximum decrease seen $72 \mathrm{~h}$ after first TAA administration (26.1 \pm 0.9 vs. $41.6 \pm 1.1 \mathrm{~g} / 1$ control values, $\mathrm{P}<0.05$ ). However, TAA did not elicit any significant decrease in plasma albumin levels in intact female rats. In the males, castration prevented the postTAA decrease in plasma albumin whereas gonadectomy did not influence plasma albumin in the females.

C

$\begin{array}{ll}\square \text { Male rats with ALF } & \square \text { Female rats with ALF } \\ \square \text { Male rats with ALF + castration } & \text { B Female rats with ALF + castration }\end{array}$

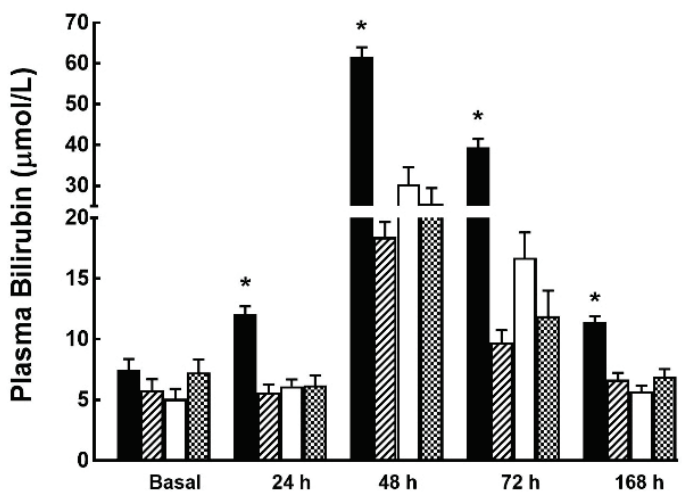

D

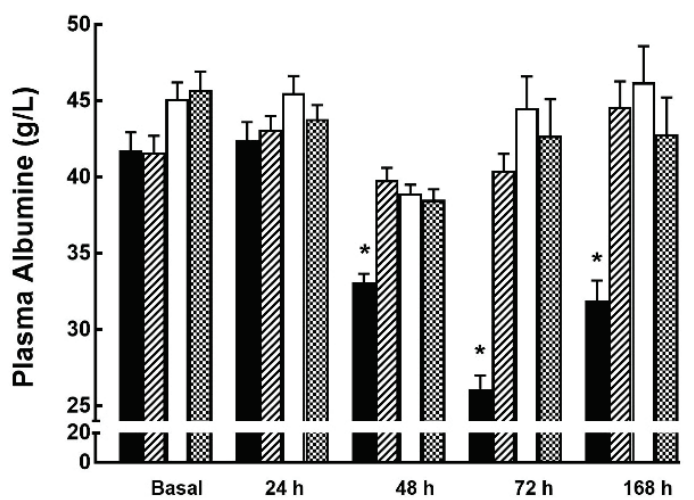

Fig. 5. Comparison of changes in $(\mathbf{A})$ plasma ammonia $\left(\mathrm{NH}_{3}\right)$ levels; $(\mathbf{B})$ plasma alanine aminotransferase (ALT) activity; (C) plasma bilirubin levels; (D) plasma albumin levels in intact and castrated male and female Lewis rats with acute liver failure (ALF) induced by thioacetamide (TAA). $* P<0.05$ vs. the unmarked values at the same time point. ${ }^{*} \mathrm{P}<0.05$ vs. corresponding values at the same time point in castrated male Lewis rats with TAA-induced ALF.

\section{Discussion}

It should first be clarified that the term "sex" defines the chromosome pattern, $\mathrm{XX}$ or $\mathrm{XY}$, characterizing each cell in the body, and is associated with biological and physiological features denoted as male or female. Dissimilarly, "gender" refers to the combination of genetic status of the subject with social, behavioral and cultural contexts (Lee 2018, Mannon et al.
2020, Straface et al. 2012, WHO - available at http://www.who.int/gender/whatisgender/en/). Therefore, "gender-related differences" cannot be explored in experimental animal studies even though this can be undertaken in clinical investigation. Therefore, in our study, only sex-related differences are studied and the term "sex" will be used as defined here.

The first important set of findings of the present study relates to sex-linked differences in the course of 
TAA-induced ALF in intact (no gonadectomy) Lewis rats. The differences consisted of lower survival rate and augmented degree of liver injury (higher plasma $\mathrm{NH}_{3}$, ALT and bilirubin levels) in intact male rats as compared with the female counterparts. In addition, the males showed augmented deterioration of biosynthetic function of the liver, as seen from a profound decrease in plasma albumin levels. In the surviving male rats, these levels were also significantly lower than in the females or in the healthy males receiving injections of physiological saline. Of special interest is the finding that intact females were relatively resistant to the development of TAA-induced ALF: The mortality but also the morbidity were low, in accordance with only moderate increases in plasma $\mathrm{NH}_{3}$ and bilirubin levels and ALT activity. Nor was the biosynthetic function of the liver dramatically impaired, because plasma albumin was not significantly reduced throughout the experiment as compared with the initial values and the values measured in healthy female rats.

The second important set of findings of the present study relates to the effect of castration on the course of TAA-induced ALF in Lewis rats. Our results show that gonadectomy did not alter the course of ALF in female rats whereas in the males castration improved the survival rate and attenuated the degree of liver injury bringing it to the level observed in their female counterparts.

Our data show that Lewis rats exhibit important sexual dimorphism of TAA-induced ALF and that the deterioration of the course of TAA-induced ALF in male rats is mediated by testosterone. On the other hand, protective effects of ovarian hormones on the course of ALF in female rats are negligible. Taken together, the data indicate that the lack of testosterone rather than presence of female hormones might be critical for attenuation of liver failure. However, it is important to acknowledge that our conclusion regarding deleterious effects of testosterone on the course of TAA-induced ALF in male Lewis rats reveals some limitation, because testosterone levels were measured in separate series of animals after gonadectomy and therefore the data regarding plasma sex hormone levels in animals exposed to TAA administration are missing. Our conclusion is based on the indirect evidence from the first series of experiments (i.e. series evaluating effects of gonadectomy on plasma testosterone and estradiol levels in healthy Lewis rats). This limitation is caused by technical reasons, because for the evaluation of plasma testosterone and estradiol levels relatively large volumes of blood samples are required, which could adversely affect the course of TAA-induced ALF concerning the survival rate, and therefore blood samples were not taken. Our findings are of special interest and consideration of a number of pertinent issues might provide some insight in the background of the observed sex-related differences.

First, it is of considerable interest that female Lewis rats are resistant to the development of TAA-induced ALF. This is so even though it has been reported that female patients are more sensitive to the drug-induced liver injury (Amacher 2014, Buzzett et al. 2017), that female primary hepatocytes are more sensitive to various hepatotoxicants (Mennecozzi et al. 2015), and that drug-induced ALF occurs more frequently in women, and the mortality is markedly higher (Miller 2001, Rubin et al. 2018, Ostapowicz et al. 2002, Stravitz and Lee 2019, Weiler et al. 2020). Admittedly, the biological mechanism for the greater susceptibility of women to drug-induced liver injury is still unknown, and neither of numerous pertinent theories proved valid (Gochfeld 2007, Miller 2001, Soldin et al. 2011, Waxman and Holloway 2009). Nevertheless, our original hypothesis was that female rats should be more susceptible to the development of TAA-induced ALF as compared with their male counterparts. Moreover, in view of the recent report that estrogen deficiency potentiated TAA-induced oxidative damage in the liver and development of hepatic fibrosis in ovariectomized female rats as compared with intact female rats or male rats (Lee et al. 2019), we also hypothesized that castration should worsen the course of TAA-induced ALF in female rats. However, neither of these hypotheses has proven to be valid.

Second, we took into consideration that low serum testosterone levels are associated with many liver diseases (particularly the non-alcoholic form) (Grossman et al. 2019, Traish 2020), and with adverse outcome of patients with cirrhosis (Sinclair et al. 2016). Moreover, it is known that male patients are less sensitive to the druginduced liver injury, including ALF (Amacher 2014, Buzzett et al. 2017). Therefore, we hypothesized that male rats should be less sensitive to the development of TAA-induced ALF as compared with the females, and that castration should deteriorate its course in the male rats. However, again, this hypothesis was not confirmed, and in fact, our results point to the contrary pattern. Therefore, of special interest is our finding that gonadectomy unequivocally improved the course of TAA-induced ALF in the males, bringing the relevant indices down to the levels observed in the intact female 
rats. This suggests very strongly that the deteriorated course of TAA-induced ALF in male rats depends on the harmful influence of testosterone. This conclusion is based on the classical experimental approach to explore sex-linked differences, i.e. on the comparison of intact animals with those after gonadectomy (Ostadal et al. 2009, Regiz-Zagrosek and Kararigas 2017); such conclusion is valid despite some limitations of our experiments. We are aware that for an ultimate conclusion comprehensive studies are needed evaluating the course of TAA-induced ALF in animals after gonadectomy, in those after gonadectomy with substitution of appropriate hormones, as well as after gonadectomy with administration of steroid hormones of the opposite sex, and also the studies of post-menopausal females, without and with hormonal substitution etc. (Ostadal et al. 2009, Regiz-Zagrosek and Kararigas 2017). All these animal groups should be subjected to experimental studies similar with those employed in the present study. Understandably, the above-defined required studies are extremely demanding and would be difficult to interpret. In this context it is important to recognize that TAA requires metabolic activation to elicit toxicity: its biotransformation to thioacetamide sulfoxide (TASO) occurs along the cytochrome P-450 (CYP)dependent pathway and then by flavin-containing monooxygenase to its reactive $\mathrm{S}$,S-dioxide thioacetamide $\left(\mathrm{TASO}_{2}\right)$. Then these reactive metabolites react with proteins by modifying lysine side chains, dramatically increase the production of reactive oxygen species, and consequently induce acute centrilobular liver necrosis (Akhtar and Sheikh 2013, Hajovsky et al. 2012, Koen et al. 2013). So far, it is recognized that TASO and $\mathrm{TASO}_{2}$ groups interact and substantially modify activity of 25 enzymes of intermediary metabolism, together with 13 enzymes of drug metabolism, which suggest the complexity of TAA-induced hepatotoxicity (Akhtar and Sheikh 2013, Hajovsky et al. 2012, Koen et al. 2013). Unfortunately, it is unknown how this TAA metabolic activation, which is necessary to elicit toxicity, is influenced by sex hormones, in our case particularly by testosterone. It is obvious that such biochemical studies are required in the future to more comprehensively understand mechanism(s) underlying TAA-induced hepatotoxicity.

In this context, it is remembered that in our previous studies using the same experimental approach (i.e. comparing intact animals with animals after gonadectomy), we documented that testosterone was an important mediator of hypertension-induced end-organ damage in the hypertensive rat transgenic for the mouse Ren-2 renin gene (TGR), a unique model of angiotensin II-dependent hypertension, and was responsible in part for poorer prognosis of heart failure (HF) in TGR (Červenka et al. 2015, Kala et al. 2019, Vaněčková et al. 2011). These findings indirectly support our belief in the adverse effects of testosterone on the course of TAA-induced ALF in Lewis rats.

The third issue deserving general consideration is the role of "sex" in animal preclinical research. The importance of sex as a biological variable (SABV) in the biomedical scientific research is increasingly recognized, due to growing acknowledgment of the significance of sex differences in various physiological and pathophysiological situations. This is largely due to the announcement by the National Institutes of Health (NIH) of a directive entitled "Consideration of SABV in NIH-Funded Research" (https://orwh.od.nih.gov/sites/ orwh/files/docs/NOT-OD-15-102_Guidance.pdf) (National Institutes of Health Office of Extramural Research). Since the NIH now expects that SABV will be factored into research designs, analyses and reporting in vertebrate animal studies, this document has a great impact on the research. When the study of only one sex is proposed, applicants are obliged to provide strong justification from the scientific literature, preliminary data or other relevant considerations. The Canadian Institute of Health Research (CIHR) (Duchesne et al. 2017) and European Union (AG Gender Position Paper 2018-2020) instituted similar polices. Therefore, even if in physiology and pharmacology the sex-related differences in experimental animals and humans are usually minimal, the evaluation of SABV in preclinical research is important. This opinion pertains also to the present study, despite the fact the sexual dimorphism pattern with regard to TAA-induced ALF in Lewis rats is contrary what has been expected based on the experience with drug-induced liver injury in patients. One can fear that if the issue of SABV were disregarded and single sex preclinical studies in ALF are employed, misleading information would be obtained. For instance, concluding from the data from female rats that TAA-induced ALF is a trivial and almost harmless disease would be incorrect and misleading, which could discourage further testing of new approaches for the treatment of ALF. Even if we accept the idea that in the field of drug-induced ALF, the "gender" differences might be more important than "sex" differences, we have to unfortunately confess, that despite 
the fact that TAA-induced ALF in Lewis rats is generally recommended for studying the pathophysiology of ALF and, in particular, for preclinical testing of new therapeutic approaches (Butterworth et al. 2009, Koblihová et al. 2015, Koblihová et al. 2020, Lima et al. 2019, Tuňon et al. 2009), our present data critically question the notion that TAA-induced ALF in Lewis rats is a fully appropriate model for studying ALF.

In conclusion, we found that Lewis rats display a remarkable sexual dimorphism with respect to TAA-induced ALF in that male rats have dramatically poorer prognosis. Our data show that testosteronemediated actions are responsible for the deterioration of the course of TAA-induced ALF in male rats. In general, our findings indicate that in the preclinical studies of pathophysiology and treatment of ALF (at least the TAA-induced ALF) the sex-linked differences should be seriously considered.

\section{Conflict of Interest}

There is no conflict of interest.

\section{Acknowledgements}

This study was supported by Ministry of Health of the Czech Republic within the project for the development of research organization 00023001 (IKEM) and MO 2012 $(\mathrm{CMH})$ - institutional support.

\section{References}

AG GENDER POSITION PAPER 2018-2020: Available http://ec.europa.eu/transparency/regexpert/index.cfm?do= groupDetail.groupDetailDoc\&id=28824\&no=1.pdf.

AKHTAR T, SHEIKH N: An overview of thioacetamide-induced hepatotoxicity. Toxin Rev 32: 43-46, 2016. https://doi.org/10.3109/15569543.2013.805144

AMACHER DE: Female gender as a susceptibility factor for drug-induced liver injury. Hum Exp Toxicol 68: 76-84, 2014. https://doi.org/10.1177/0960327113512860

BERNAL W, HYYRYLAINEN A, GERA A, AUDIMOOLAM VK, MCPHAIL MJ, AUZINGENR G, RELA M, HEATON N, O'GRADY JG, WENDON J, WILLIAMS R: Lessons from look-back in acute liver failure? A single center experience of 3300 patients. J Hepatol 59: 74-80, 2013. https://doi.org/10.1016/j.jhep.2013.02.010

BIZZARO D, CRESCENCI M, DI LIDDO R, ARCIDIACONO D, CAPPON A, BERTALO T, AMODIO V, TASSO A, STEFANI A, BERTAZO V, GERMANI G, FRASSON C BASSO G, PARNIGOTTO P, ALISON MR, BURRA $P$, CONCONI MT, RUSSSO FP: Sex-dependent differences in inflammatory responses during liver regeneration in a murine model of acute liver injury. Clin Sci 132: 255-272, 2017. https://doi.org/10.1042/cs20171260

BUTTERWORTH RF, NORENBERG MD, FELIPO V, FERENCI P, ALBRECTH J, BLEI AT: Experimental models of hepatic encephalopathy: ISHEN guidelines. Liver Int 29: 783-788, 2009. https://doi.org/10.1111/j.14783231.2009.02034.x

BUZZETTI E, PARIKH PM, GERUSSI A, TSOCHATZIS E: Gender differences in liver disease and the drug-dose gender gap. Pharmacol Res 120: 97-108, 2017. https://doi.org/10.1016/j.phrs.2017.03.014

ČERVENKA L, ŠKAROUPKOVÁ P, KOMPANOWSKA-JEZIERSKA E, SADOWSKI J: Sex-linked differences in the course of chronic kidney disease and congestive heart failure: a study in 5/6 nephrectomized Ren-2 transgenic hypertensive rats with volume overload induced using aorto-caval fistula. Clin Exp Pharmacol Physiol 43: 883-895, 2016. https://doi.org/10.1111/1440-1681.12619

DOCHERTY JR, STANFORD SC, PANATTIERI RA, ALEXANDER SPH, CIRINO G, GEORGE CH, HOYER D, IZZO AA, JI Y, SOBEY CG, STANLEY P, STEFANSKA G, TEIXEIRA M, AHLUWALIA A: Sex: a change in our guidelines to authors to ensure that this is no longer an ignored experimental variable. Br $\mathrm{J}$ Pharmacol 176: 4081-4086, 2019. https://doi.org/10.1111/bph.14761

DUCHESNE A, TANNENBAUM C, EINSTEIN G: Funding agency mechanisms to increase sex and gender analysis. Lancet 289: 699-700, 2017. https://doi.org/10.1016/s0140-6736(17)30343-4

FYFE B, ZALDANA F, LIU C: The pathology of acute liver failure. Clin Liver Dis 22: 257-268, 2018. https://doi.org/10.1016/j.cld.2018.01.003

GOCHFELD M: Framework for gender differences in human and animal toxicology. Environ Res 104: 4-21, 2007. https://doi.org/10.1016/j.envres.2005.12.005 
GROSSMANN M, WIERMAN ME, ANGUS P, HANDELSMAN DJ: Reproductive endocrinology of nonalcoholic fatty liver disease. Endocr Rev 40: 417-446, 2019. https://doi.org/10.1210/er.2018-00158

GUSTAFSSON JA, MODE A, NORSTEDT G, SKETT P: Sex steroid induced changes in hepatic enzymes. Annu Rev Physiol 45: 51-60, 1983. https://doi.org/10.1146/annurev.ph.45.030183.000411

HAJOVSKY H, HU G, KOEN Y, SARMA D, CUI W, MOORE DS, STAUDINGER JL, HANZLIK RP: Metabolism and toxicity of thioacetamide and thioacetamide S-oxide in rat hepatocytes. Chem Res Toxicol 25: 1955-1963, 2012. https://doi.org/10.1021/tx3002719

KALA P, ČERVENKA L, ŠKAROUPKOVÁ P, TÁBORSKÝ M, KOMPANOVSKA-JEZIERSKA E, SADOWSKI J: Sex-linked differences in the mortality in Ren-2 transgenic hypertensive rats with aorto-caval fistula: effects of treatment with angiotensin converting enzyme alone and combined with inhibitor of soluble epoxide hydrolase. Physiol Res 68: 589-601, 2019. https://doi.org/10.33549/physiolres.934094

KOBLIHOVÁ E, MRÁZOVÁ I, VERNEROVÁ Z, RYSKA M: Acute liver failure induced by thioacetamide: selection of optimal dosage in Wistar and Lewis rats. Physiol Res 63: 491-503, 2014. https://doi.org/10.33549/physiolres.932690

KOBLIHOVÁ E, LUKŠAN O, MRÁZOVÁ I, RYSKA M, ČERVENKA L: Hepatocyte transplantation attenuates the course of acute liver failure induced by thioacetamide in Lewis rats. Physiol Res 64: 689-700, 2015. https://doi.org/10.33549/physiolres.932914

KOBLIHOVÁ E, MRÁZOVÁ I, VAŇOURKOVÁ Z, MAXOVÁ H, KIKERLOVÁ S, HUSKOVÁ Z, RYSKA M, FRONĚK J, VERNEROVÁ Z: Pharmacological stimulation of Wnt/ $\beta$-catenin signaling pathway attenuates the course of thioacetamide-induced acute liver failure. Physiol Res 69: 113-126, 2020. https://doi.org/10.33549/physiolres.934071

KOEN YM, SARMA D, HAJOVSKY H, GALEVA NA, WILIAMS TD, STAUDINGER JL, HANZLIK RP: Protein targets of thioacetamide metabolites in rat hepatocytes. Chem Res Toxicol 26: 564-574, 2013. https://doi.org/10.1021/tx400001x

LEE KS: Sex as an important biological variable in biomedical research. BMP Rep 51: 167-173, 2018. https://doi.org/10.5483/bmbrep.2018.51.4.034

LEE YH, SON JY, KIM KS, PARK YJ, KIM HR, PARK JH, KIM KB, LEE KY, KANG KW, KIM IS, KACEW S, LEE BM, KIM HS: Estrogen deficiency potentiates thioacetamide-induced hepatic fibrosis in Sprague-Dawley rats. Int J Mol Sci 20: 3709, 2019. https://doi.org/10.3390/ijms20153709

LIMA LCD, MIRANDA AS, FERREIRA RN, RACHID MA, SIMOES E SILVA AC: Hepatic encephalopathy: lessons from preclinical studies. Word J Hepatol 11: 173-185, 2019. https://doi.org/10.4254/wjh.v11.i2.0000

MANNON EC, RAY SC, RYAN MJ, SULLIVAN JC: Does sex matter?: an update on the implementation of sex as a biological variable in research. Am J Physiol Renal Physiol 318: F329-F331, 2020. https://doi.org/10.1152/ajprenal.00575.2019

MARCOS R, CORREIA-GOMES C, MIRANDA H, CARNEIRO F: Liver gender dimorphism - insights from quantitative morphology. Histol Histopathol 30: 1431-1437, 2015. https://doi.org/10.14670/HH-11-648

MENNECOZZI M, LADESMANN B, PALOSAARI T, HARRIS G, WHELAN M: Sex differences in liver toxicity do female and male human primary hepatocytes react differently to toxicants in vitro? PLoS One 10: e0122786, 2015. https://doi.org/10.1371/journal.pone.0122786

MILLER MA: Gender-based differences in the toxicity of pharmaceuticals: the Food and Drug Administration's perspective. Int J Toxicol 20: 149-152, 2001. https://doi.org/10.1080/109158101317097728

NATIONAL INSTITUTES OF HEALTH OFFICE OF EXTRAMURAL RESEARCH: Consideration of sex as a biological variable in NIH-funded research. Available: https:/orwh.od.nih.gov/sites/orwh/files/docs/NOTOD-15-102_Guidance.pdf.

OSTADAL B, NETUKA I, MALY J, BESIK J, OSTADALOVA I: Gender differences in cardiac ischemic injury and protection - experimental aspects. Exp Biol Med (Maywood) 234: 1011-1019, 2009. https://doi.org/10.3181/0812-mr-362

OSTAPOWICZ G, FONTANA RJ, SCHODT FV, LARSON A, DAVERN TJ, HAN SH, MCCASHLAND TM, SHAKIL AO, HAY JE, HYNAN L, CRIPPIN JS, BLEI AT, SAUMEL G, REISCH J, LEE WM, U.S. ACUTE LIVER 
FAILURE GROUP: Results from a prospective study of acute liver failure at 17 tertiary care centers in the United States. Ann Intern Med 137: 947-954, 2002. https://doi.org/10.7326/0003-4819-137-12-200212170-00007

PATEL P, OKORNKWO N, PYRSOPOULOS NT: Future approaches and therapeutic modalities for acute liver failure. Clin Liver Dis 22: 419-427, 2018. https://doi.org/10.1016/j.cld.2018.01.011

REGITZ-ZAGROSEK V, KARARIGAS G: Mechanistic pathways of sex differences in cardiovascular disease. Physiol Rev 97: 1-37, 2017. https://doi.org/10.1152/physrev.00021.2015

REUBEN A, TILLMAN H, FONTANA RJ, DAVERN T, MCGUIRE B, STRAVITZ RT, DRUKALSKI V, LARSON AM, LIOU I, FIX O, SCHILSKY M, MCCASHLAND T, HAY JE, MURAY N, SHAIKH OS, GANGER D, ZAMAN A, HAN SB, CHUNG RT, SMITH A, ET AL.: Outcomes in adults with acute liver failure between 1998 and 2013: and observational cohort study. Ann Intern Med 164: 724-732, 2016. https://doi.org/10.7326/m15-2211

RUBIN JB, HAMMED B, GOTTFRIED M, LEE W, SARKAR M, ACUTE LIVER FAILURE STUDY GROUP: Acetaminophen-induced acute liver failure is more common and more severe in women. Clin Gastroenterol Hepatol 16: 936-946, 2018. https://doi.org/10.1016/j.cgh.2017.11.042

SCHOTTEN D, TREBLICKA J, LIEDTKE C, WEISKIRCHEN R: The carbon tetrachloride model in mice. Lab Anim 49: 4-11, 2015. https://doi.org/10.1177/0023677215571192

SINCLAIR M, GOW PJ, GROSSMANN M, SHANNON A, HOERMANN R, ANGUS PW: Low serum testosterone is associated with adverse outcome in men with cirrhosis independent of the model of end-stage liver disease score. Liver Transpl 22: 1482-1490, 2016. https://doi.org/10.1002/1t.24607

SOLDIN OP, CHUNG SH, MATTISON DR: Sex differences in drug disposition. J Biomed Biotechnol 187103: 1-14, 2011.

STRAFACE E, GAMBARDELLA L, BRANDANI M, MALORNI W: Sex differences at cellular level: "cells have a sex". Handb Exp Pharmacol 214: 49-65, 2012. https://doi.org/10.1007/978-3-642-30726-3 3

STRAVITZ RT, LEE WM: Acute liver failure. Lancet 394: 869-881, 2019. https://doi.org/10.1016/S01406736(19)31894-X

SUCHY FJ: Hepatobiliary function. In: Medical Physiology. BORON WF, BOULPAEP EL (eds 2nd edition), Saunders Elsevier, Philadelphia, PA, USA, 2009, pp 980-1008.

SUTTI S, TACKE F: Liver inflammation and regeneration in drug-induced liver injury: sex matters! Clin Sci 132: 609-613, 2018. https://doi.org/10.1042/cs20171313

TRAISH AM: Health risk associated with long-term finasteride and dutasteride use: it's time to sound the alarm. World J Mens Health 38: 323-337. https://doi.org/10.5534/wjmh.200012

TSUKAMOTO I, KOJO S: The sex difference in the regulation of liver regeneration after partial hepatectomy in the rat. Biochim Biophys Acta 1033: 287-290, 1990. https://doi.org/10.1016/0304-4165(90)90135-j

TUÑÓN MJ, ALVAREZ M, CULEBRAS JM, GONZÁLES-GALLEGO J: An overview of animal models for investigating the pathogenesis and therapeutical strategies in acute hepatic failure. Word J Gastroenterol 15: 3086-3098, 2009. https://doi.org/10.3748/wig.15.3086

VANĚČKOVÁ I, HUSKOVÁ Z, VAŇOURKOVÁ Z, ČERVENKA L: Castration has antihypertensive and organoprotective effects in male but not in female heterozygous Ren-2 rats. Kidney Blood Press Res 34: 46-52, 2011. https://doi.org/10.1159/000322618

WAXMAN DJ, HOLLOWAY MG: Sex differences in the expression of hepatic drug metabolizing enzymes. Mol Pharmacol 76: 215-228, 2009. https://doi.org/10.1124/mol.109.056705

WAXMAN DJ, O'CONNOR C: Growth hormone regulation of sex-dependent liver gene expression. Mol Endocrinol 20: 2613-2629, 2006. https://doi.org/10.1210/me.2006-0007

WEILER N, SCHLOTMANN A, SCHNITZBAUER AA, ZEUZEM S, WELKER MV: The epidemiology of acute liver failure. Dtsch Arztebl Int 117: 43-50, 2020. https://doi.org/10.3238/arzteb1.2020.0043

WHO: What do we mean by “sex" and "gender"? Available: http://www.who.int/gender/whatisgender/en/.

ZUCKER I, BEERY AK: Studying sex as a biological variable: is a new day dawning? J Womens Health (Larchmt) 28: 1-2, 2019. https://doi.org/10.1089/jwh.2018.7598 